\title{
The e-Heritage project of Valencian catalogues
}

\author{
M. T. Broseta \\ Instituto Universitario de Restauración del Patrimonio, \\ Universidad Politécnica de Valencia, España
}

\begin{abstract}
The complexity by the spread of heritage protection plans justifies the need to implant ICT to handle the extensive documentation belonging to heritage catalogues, which are the base of a good work of preservation and renovation for new activities in buildings.

The disconnected information obtained from several cataloguing works in the Valencian Community, makes evident the great advance that would be to do a digital data base that collected updated technical and legal information of all catalogued buildings.

This objective sustains SIPACV: "Valencian e-Heritage Project", an information system of Valencian Architectural Heritage, with incorporation of a Geographical Information System (GIS), and buildings cartographic reference, added to technical and legal information index cards; all of this focused to the management of heritage renovation.
\end{abstract}

Keywords: e-Heritage system, catalogue, architectural heritage, Valencia.

\section{Introduction}

The application of information and communications technology (ICT) and a geographic information system (GIS) to architectural heritage brings up some examples of E-heritage projects developed in Europe; among others, the DART Project at Cassino University [1], about the analysis of medium and small size Latium historical districts, the SIArch-Univaq project of the Architecture and Urbanism Department at L'Aquila University about GIS databases for architecture, the computing system cataloguing of historic plaster of Venice City [2] or the information system of the archaeological site of Pompeii, at the Architecture Department of Bologna University. 
"The key words for architectural heritage future are network, memory, identity, use and communication. Public administrations with culture competition are responsible for enabling and managing cultural heritage catalogues that today must be designed in accordance with digital standards and sharing digital platforms resources. Therefore it is essential to provide a cultural heritage index, improving existing databases, making them visible to the general public, operational and flexible by means of building multimedia files that offer structured and concise information" (Bartolomei [3]).

The advances in new information technologies have made the public administrations equip themselves with high capacity computers that could allow them a significantly higher efficiency implementing these projects than provided right now.

Considering urban management, the vast information due to urban plans, justifies the need to implement digital information systems to encompass the complex data of municipal built heritage catalogues, in order to collect updated physical description and norms of listed buildings, being the basis for a good job of protecting and recovering for new activities.

Valencian urban planning law (LOTUP) emphasizes the need to a homogeneous data gathering, what supposes municipal computing resources appropriated for fast and effective listed items search, not only as a unit, but also generic, selecting different features, with its corresponding and immediate location on the city plane.

\section{Background}

\subsection{TICS at architectural heritage registers}

The states that signed the Treaty of Granada Convention (1985), agree to exchange their conservation policies regarding inventory, protection and preservation methods, taking into account historical development, architectural heritage gradual increase and possibilities offered by new technologies to identification and registration, scientific research, restoration work and management methods and architectural heritage animation.

According to Bartolomei's thesis, guidelines for efficient architectural heritage management provide that the documentation phase is necessary to acquire knowledge, to understand meaning and value and to promote people interest and involvement, so there is a valid management method to ensure protection and long-term preservation.

The information acquisition must be prior, during and after the restoration and must be performed by a qualified team of professionals with interest and respect for heritage. The documentation activity must converge in a database where for each catalogued object is defined clearly and precisely the location, sources, metric data and qualitative and quantitative information.

The systematic recording of Portuguese collections developed by Ministry of Culture agencies establishes the basis of heritage promotion policies to national identity and culture democratization benefit. The Portuguese Institute of 
Architectural and Archaeological Heritage Management (IGESPAR) has an online database, whose geo-reference and access system allows a good number of cross searches about heritage through the Ulisses system.

In Italy SIGECweb [4], General Informative System of the Italian Catalogue depending on the Central Institute for Cataloguing and Documentation (ICCD), from Italian Ministry of Goods and Cultural Activities, is born in 2004 in order to unify and streamline cataloguing process.

The heritage database of Andalucía [5] stands out in Spain because of its telematic resources. The consulting web of Cultural Property in Andalucía (MOSAIC) includes: Andalucian Historical Heritage General Catalogue, which provides identification and basic information about administrative record; cartographic locator with geographic visual interface for several cartographic databases; Andalucian Architectural Heritage Database, which allows general inquiries on archaeological, architectural and ethnological heritage and finally Contemporary Architecture Data Base, Cultural Heritage Image Bank, Historical Heritage Thesaurus (TPHA) and Restored Works Catalogue by the Andalucian Historical Heritage Institute since 1990.

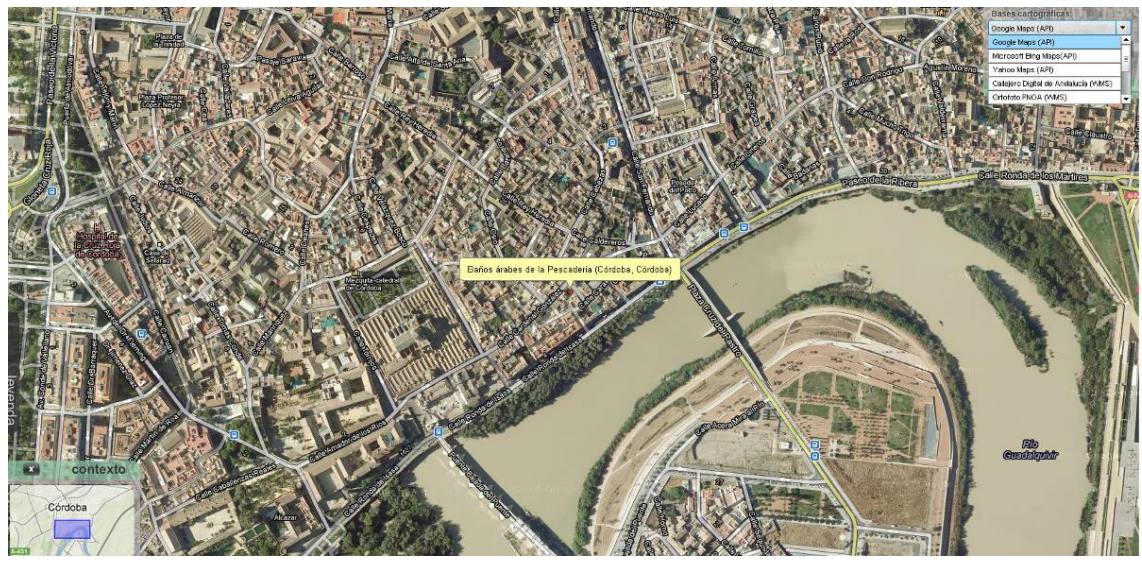

Figure 1: Geographic locator linked to the Andalucía Heritage Property Database. Location consulting can be done from different geographic bases: Google maps (API), Microsoft Bing Maps (API), Yahoo Maps (API), Andalucía Digital Map (WMS) and Orthophoto from Aerial Orthophoto National Plan, PNOA (WMS).

\subsection{The multiplicity of municipal heritage catalogues}

The municipal catalogues, beyond the inventories of goods express declared to be of cultural interest, contain most of our built heritage and regulate its preservation and future use in hands of local government.

The municipal catalogue, as a unique and general document in the General Plan, must contain all heritage elements in the township. However, in the Valencian Community the interpretation of incorporating a new catalogue in 
each development plan, instead of the municipal catalogue revision, contributes to the multiplicity of catalogues and the superposition of heterogeneous contents, from different protection plans. This becomes just gibberish data and a complex scene for heritage management by government, owners and professionals.

Tools for suitable data processing are missing; new technologies have not reached the field of heritage protection in the first level: the cataloguing. This field with contents more profuse each day with the contribution of supra-local plans and landscape catalogues, emerging in the Valencian scene nowadays, are impossible to cover by users through traditional means of knowledge acquisition.

Table 1: List of Special Protection Plans in Valencia and their amending documents that have buildings newly-catalogued, unlisted or modified with respect to municipal catalogue.

\begin{tabular}{|c|c|c|}
\hline HERITAGE PROTECTION SPECIAL PLANS WITH CATALOGUE & $\begin{array}{l}\text { APPROVAL } \\
\text { DATE }\end{array}$ & $\begin{array}{l}\text { NUMBER OF } \\
\text { CATALOGUED } \\
\text { ELEMENTS }\end{array}$ \\
\hline Special Plan of Protection \& Inner Renovation in Carme District & 18/06/1991 & 364 \\
\hline SP Protection \& Inner Renovation in Campanar (T-5) & $27 / 06 / 1992$ & 62 \\
\hline SP Protection \& Inner Renovation in Velluters District & $22 / 10 / 1992$ & 231 \\
\hline SP Protection \& Inner Renovation in Seu-Xerea District & $01 / 02 / 1993$ & 413 \\
\hline SP Protection \& Inner Renovation in Mercat District & 13/04/1993 & 453 \\
\hline $\begin{array}{l}\text { SP Protection \& Inner Renovation in Universitat-Sant Francesc } \\
\text { District }\end{array}$ & 08/0 1/1993 & 340 \\
\hline SP Protection \& Inner Renovation in Patraix (A-3) & 11/11/1993 & 31 \\
\hline $\begin{array}{l}\text { SP Protection \& Inner Renovation M-4 in Cabanyal-Canyamelar } \\
\text { SP Protection in Alqueria de Bola surroundings }\end{array}$ & $\begin{array}{l}24 / 06 / 2001 \\
19 / 02 / 2003\end{array}$ & 560 \\
\hline SP PEP-1 Expansion District Pla del Remei-Russafa Nord & $14 / 02 / 2006$ & 297 \\
\hline SP Protection in Senda de Llora and its surrounding (La ZAL) & $24 / 08 / 2006$ & 7 \\
\hline SP PEP-2 Expansion District Russafa Sud Gran Vía & $05 / 04 / 2007$ & 402 \\
\hline $\begin{array}{l}\text { SP Conservation \& Preservation of Plaza Redonda in Mercat } \\
\text { District }\end{array}$ & $10 / 04 / 2007$ & 33 \\
\hline $\begin{array}{l}\text { SP Protection of Monument surrounding of Nuestra Señora de la } \\
\text { Misericordia de Campanar church }\end{array}$ & $\begin{array}{l}\text { Being } \\
\text { processed }\end{array}$ & 31 \\
\hline $\begin{array}{l}\text { SP Project of Monument surrounding of San Vicente de la Roqueta } \\
\text { church and Monastery }\end{array}$ & $\begin{array}{l}\text { Being } \\
\text { processed }\end{array}$ & NO INFO \\
\hline $\begin{array}{l}\text { SP Protection of Monuments Surrounding: Puerta de Serranos, } \\
\text { Santo Domingo, San Pio V, Temple, Justicia, Carmen y Cervelló }\end{array}$ & $\begin{array}{l}\text { Being } \\
\text { processed }\end{array}$ & 136 \\
\hline \multicolumn{3}{|l|}{$\begin{array}{l}\text { AMENDING PLANNING THAT CONCERNS THE MUNICIPAL } \\
\text { CATALOGUE }\end{array}$} \\
\hline $\begin{array}{l}\text { Amending Special Plan of Protection and Inner Renovation (SPPIR) } \\
\text { in Seu-Xerea District, N3 of Luis Vives Street. }\end{array}$ & $31 / 12 / 2003$ & 1 \\
\hline $\begin{array}{l}\text { Amending SPPIR in Carme District, Guillem de Castro, Lliria and } \\
\text { Gutenberg Streets. }\end{array}$ & $24 / 02 / 2006$ & 4 \\
\hline Amending SPPIR in Carme District, Wall Muslim & $24 / 02 / 2006$ & 2 \\
\hline Amending SPPIR in Seu-Xerea District, N4, Trinitarios Street & $23 / 03 / 2006$ & 1 \\
\hline $\begin{array}{l}\text { Amending SPPIR in Carme District, N3,5,7 and 9, Beneficencia } \\
\text { Street }\end{array}$ & $14 / 04 / 2005$ & 4 \\
\hline Amending SPPIR in Seu-Xerea District, Cerveró Palace & $\begin{array}{l}\text { Being } \\
\text { processed }\end{array}$ & NO INFO \\
\hline $\begin{array}{l}\text { Amending SPPIR in Seu-Xerea District, N31, del Mar Street, } \\
\text { (Valeriola Palace) and San Cristóbal Street }\end{array}$ & 08/03/2010 & 2 \\
\hline $\begin{array}{l}\text { Amending SPPIR in Velluters District, Block delimited by Quart, } \\
\text { Palomar, Murillo, Moro Zeit and Rey Don Jaime Streets }\end{array}$ & $\begin{array}{l}\text { Being } \\
\text { processed }\end{array}$ & 7 \\
\hline Amending SPPIR in Carme District by AUMSA & $04 / 08 / 2001$ & 10 \\
\hline Amending SPPIR in Seu-Xerea District by AUMSA & $05 / 02 / 2003$ & 2 \\
\hline Amending SPPIR in Velluters District by AUMSA & $16 / 11 / 2004$ & 6 \\
\hline
\end{tabular}


We can affirm that in one township as Valencia, we can find one municipal catalogue and a series of "catalogues" with different scopes, whose content adjusts or not to the current legislation, which are supplementing or modifying the first one. Besides there are amending documents for the General Plan and Detail Plans that can introduce changes to the general catalogue, like the structural catalogue in the Simplified Revision of the General Plan of Valencia, on top of the Catalogue of Goods and Protected Rural Areas in the Territorial Action Plan for the Protection of the Vegetable Garden, Landscape Catalogues, of local or regional scope, and Catalogues in Special Protection Plans for inventoried buildings and their surroundings.

\subsection{The administrative register contribution to the catalogue of Valencia City}

The review of municipal catalogues are essential for the conservation of urban heritage, in this sense Valencia City Council has recently presented the structural revision of municipal catalogue and has hired an ambitious project to draft special protection plans for monuments surroundings in Historical District.

The effort to review is remarkable, although only covers a small portion, only goods included in the General Inventory of Valencian Heritage, compared to the more than 3,800 catalogued properties, therefore, the improvement of identification, location, surrounding delimitation and protection regime is applied only for those buildings of monumental character.

The figure of unique catalogue should be reached, to clarify and simplify and to meet the objectives set by two laws: the detailed inventory of buildings belonging to historical districts or monument protective surroundings, and the inclusion of real estate of cultural interest from the township scope.

The catalogue purpose is to establish a legal framework in order to protect the building, based on the values it holds; and therefore the required documentation should be that which provide us the following information about the construction:

a) Exact physical location: demarcation map and cadastral reference.

b) Legal status: landowner or landlord, land classification, sectoral legislation conditions and information that constrains the type of intervention and the protection level.

c) Type of intervention: uses regulation and possible administrative activities with the purpose of conservation.

d) Level or degree of protection: how to intervene from the technical point of view, distinguishing between full, partial and environmental protection.

Secondly there must be a principle of equality and justice underlying in cataloguing, therefore the regulatory regime must keep an agreement, fixed by law, between protection levels and types of technical intervention on buildings, so that this connection should not be subject to the discretional nature of creating new criteria in each catalogue. 


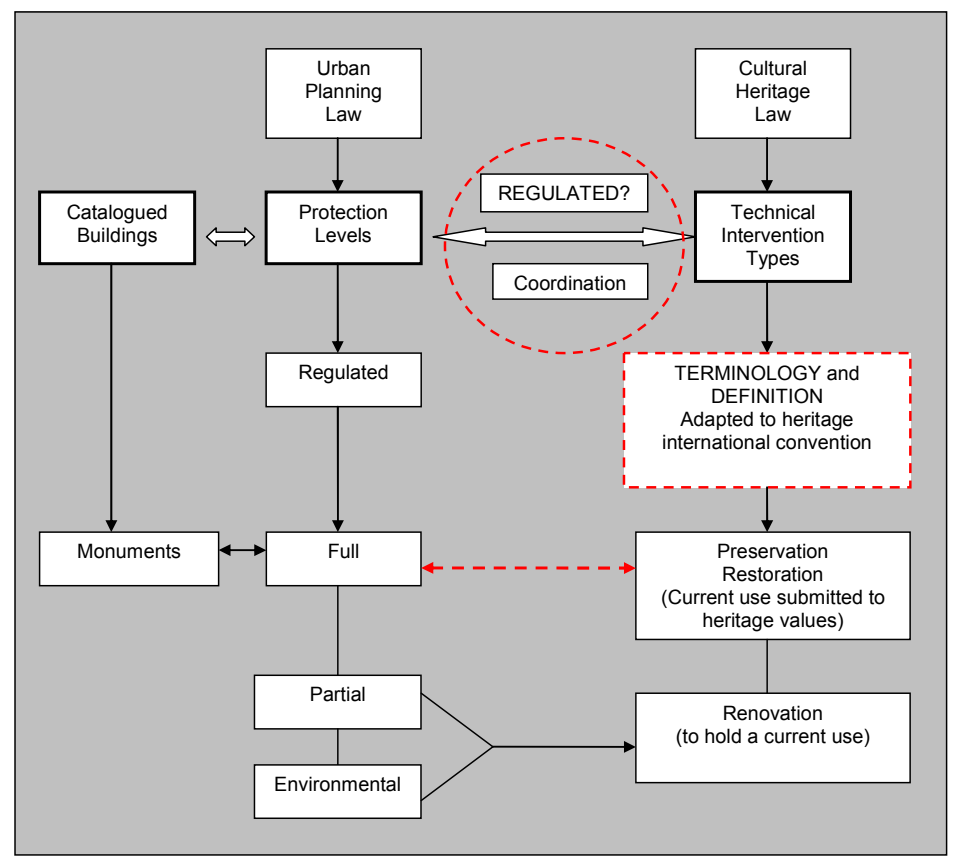

Figure 2: Connection between regulated protection levels and technical intervention criteria.

\section{SIPACV: Valencia e-Heritage project}

SIPACV project is born as a resource to correct the lacks discussed above with the following objectives:

- Access to culture as a socially claimed demand by a consumer sick of material products, who seeks experiences based on intangibles, linked to cultural resources: monographs, guides, thematic publications, etc.

- Cultural productive profit based on tourist use, especially architectural heritage as incentive of economic and social city development in the future Strategic Plan of Culture.

- Cultural heritage reinventing with itineraries or cultural districts related to celebrities, periods or subjects that promote cultural diversity, respect for human rights and peace.

- Promotion and assessment of the historical districts through their knowledge as cultural and real estate product.

- Enabling tools that improve the effective cultural and urban management of the consolidated city and sustainability through the use of new technologies.

- Incorporating geographic and cartographic information technologies (ICT) in local government in compliance with EU Directive 2007/2/EC, for spatial information establishment (Inspire). 
- Enabling public participation at environmental and cultural heritage fields. (In compliance with Law 27/2006 of July 18th, by which the rights of access to information, public participation and access to justice in environmental matters are regulated - incorporates the Directives 2003/4/CE and 20037357CE.)

These objectives underpin the SIPACV Project, consisting in an information system and images bank of Architectural Heritage of Valencian Community with a Geographic Information System (GIS) and mapping locator, and the addition of a technical and legal information system focused on restoration management.

In summary, taking Valencia Township as an example, the project would begin by identification working phase, where existing data in original Valencia paper register of 1993 would be checked considering newer records which can give room to data overlaps. Later it would continue with the building documentation phase, introducing in database prior references to its physical description, if any, and state of preservation at the time of the system production; and at last, it would come the effort to standardize the profuse legal regime applicable to buildings from each planning document.

\subsection{System description: SIPACV software}

SIPACV software defines a dual information system: full internal management (using municipal mapping service) and limited public access to resources, as well as the standardization and unification of protection catalogue cards (obtained from Heritage Inventory and previous catalogues commented), where the standards in contents proposed must anticipate the software works. (The general requirements of SIPACV software: the use of web technologies, portability, modularity, free software, and others, such as GUI, GIS databases, automatic generation of file cards and GIS maps, management support of references and working stages approach, have been developed for the project by the architect José Juan Oliva Martí.)

Specialized technical team is required for software development, in particular in the treatment of freely distributed databases, with special attention to universal connection established by administrations.

Georeference and geographic database has already been tested at a previous project 'Geon' applied in a defined area, such as the Historical District of Burriana (Castellón-SP).

The standards for the catalogue cards let us establish a structured database around the georeferencing (either by spatial positioning or by the cadastral reference). Thus, protected elements are univocal identified on the territory, while a number of features are assigned, coincident with catalogue cards settings.

This approach is not unknown for public administration: nowadays, the Generalitat Valenciana has tools in compliance with these targets for other fields of work (such as green infrastructure, parks, biodiversity, waste generation, flood risk...). These are public information tools as Terrasit or the Cartographic Viewer of Valencia Community (Citma) developed by the Cartographic Institute of Valencia. 
The program will enable the data gathering according to defined criteria for subsequent treatment using specific search fields or geographic inquiries. This system has the advantage of providing all necessary data from a building or area, in a clear and visual manner. Besides this is a dual capacity, while public available information is bounded, information for technical services is complete and can be connected with other administrative services (official land register, urban planning, facilities, environment, etc.).

With all this, we must consider this management system is designed to be 'exportable' to the whole Valencian Community scope, and therefore to smaller local entities. Forced by this aspect, systematization and standardization are necessary requirements to guarantee the software usefulness.

\subsection{The pyramid of users}

Tool development takes into account all legal considerations provided in the Municipal Ordinance of Electronic Administration Use of Valencia City.

According to the norm, it is established the pyramid of users who will interrelate with the software, limiting access to information and benefits depending on the type of user defined.

Access to the Municipal Web let users research heritage data (users level access), while the access for administration technicians to data program and existing repository and digitization, allows the effective governmental guardianship (intermediate level access), and finally, the restricted access level to data sources is only available for Computer Support Service of the Town Hall and those agents who were involved in the collection and data modification (loading program).

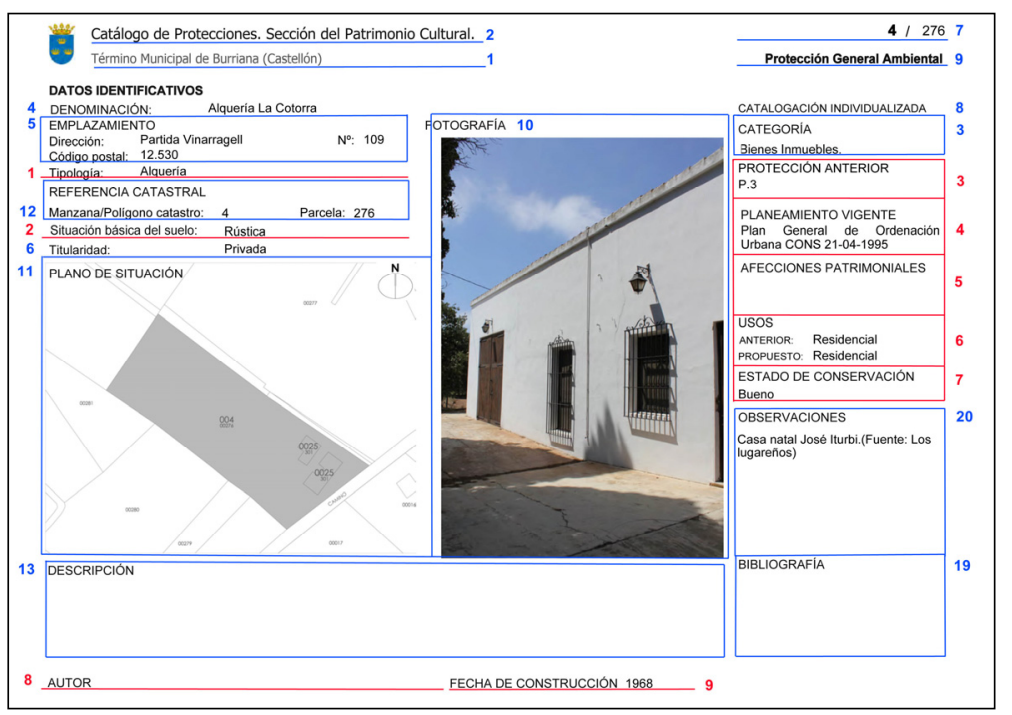

Figure 3: Proposed catalogue index card for SIPACV software. 
The benefits at user level are the easy, free and permanent access to any kind of urban information such as updated planning instruments, and safety and reliability of available reports, which would assure possible private investment in heritage restoration.

The benefits to municipal technicians are the planning norms instant consult, in safe and effective way and automatic mode reporting.

The benefit at restricted level of original data source is the safely and single format availability, with specific control over changes made.

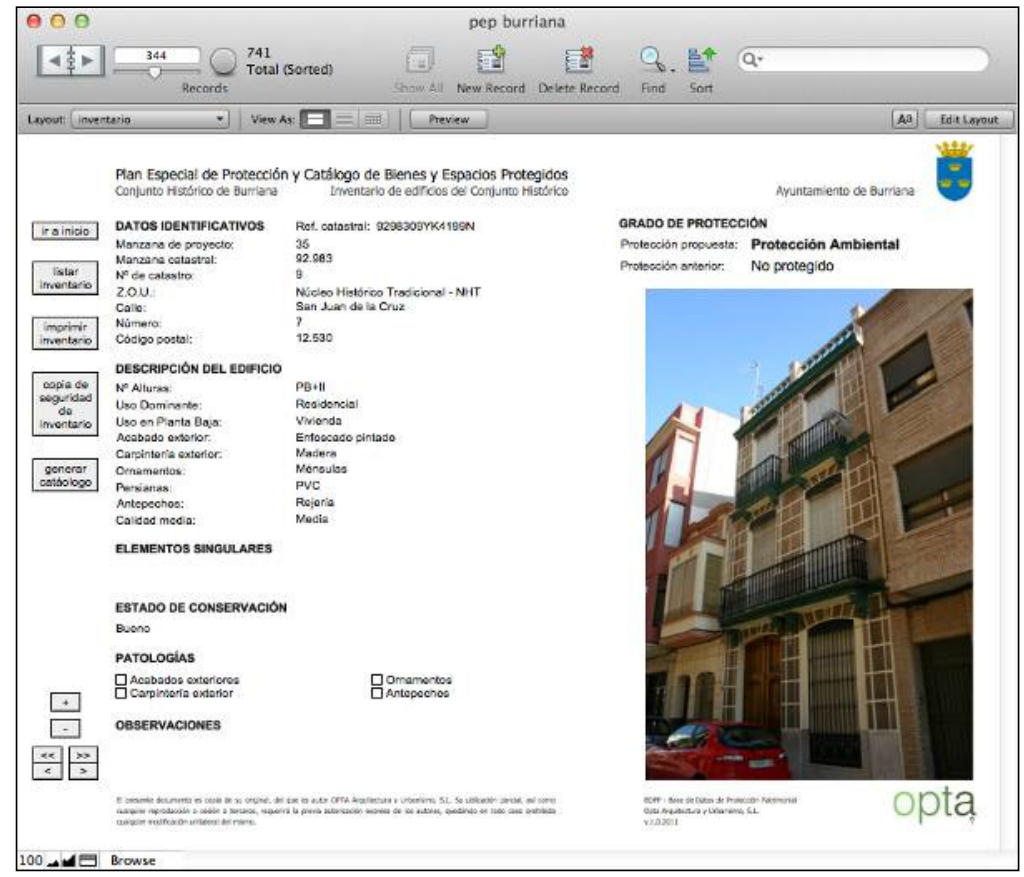

Figure 4: Geon software: protected buildings inventory for the Special Protection Plan of the Historical District of Burriana (Castellón).

\subsection{The system application to the catalogue of the Special Protection Plan of the Historical District of Burriana (Castellón)}

As noted above, the potential use of SIPACV has been tested in a previous case: a section of explained software has been developed for the Special Protection Plan for the Historical District of Burriana. It was a smaller application than that proposed here, but with a similar technological base: the database interrelation with georeferenced items. (The "Geon Project" version v.1.0.2011 has been elaborated and coordinated by the architects Francisco Taberner Pastor and José Juan Oliva Martí, OPTA, Arquitectura y Urbanismo S.L.)

In the case of Burriana, a data load program was produced but not connected to any central server, due to local administration lacked this service maps. It is 
easy to envision this tool potential if completed with the technical proposals discussed: scale use, levels access based in pyramid users and use of existing administrative services at Town Halls.

The initial program load screen shows the main options use: 1) Prior documentation introduction; 2) Buildings inventory generation; 3) Reports automatic generation according to criteria; 4) Load data and protected building catalogue generation; 5) Detailed building information; 6) Applicable regulations; 7) Graphical ordinance; 8) Data and users management; 9) Search panel according to standard concepts.

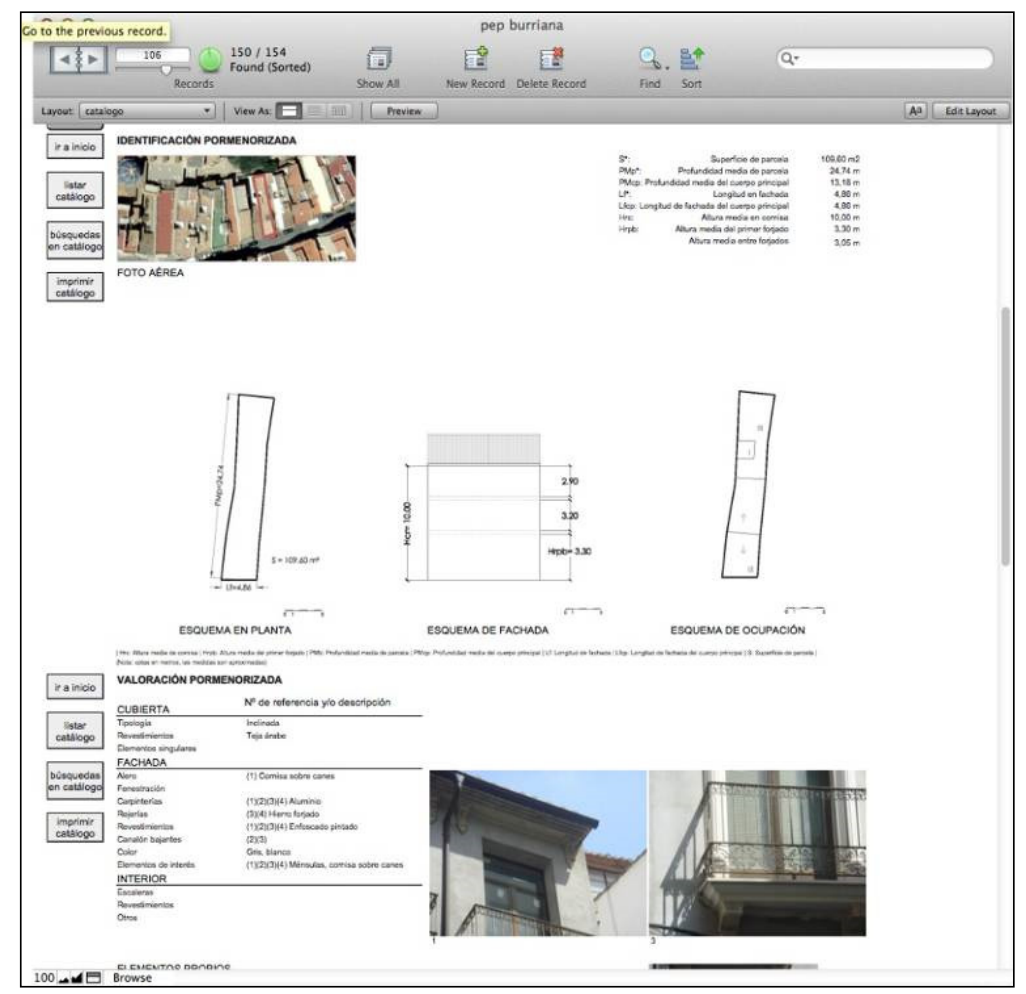

Figure 5: Detailed building information screen of Geon System, for Architectural Heritage in Historical District of Burriana.

\subsection{Methodology}

Works planned for SIPACV implementation are set based on four stages set on the concept of 'true datum': a single record from the beginning for each listed element, which facilitates monitoring and control by the editor team and involved administrations. 
Table 2: Methodology and development stages of the SIPACV project.

\begin{tabular}{|c|c|c|c|}
\hline $\begin{array}{c}\text { STAGE I } \\
\text { Catalogued elements } \\
\text { Identification }\end{array}$ & $\begin{array}{c}\text { STAGE II } \\
\text { Previous data gathering }\end{array}$ & $\begin{array}{c}\text { FASE III } \\
\text { New data gathering }\end{array}$ & $\begin{array}{c}\text { FASEIV } \\
\text { Index cards review }\end{array}$ \\
\hline $\begin{array}{l}\text { Buildings List } \\
\text { Cadastral reference } \\
\text { identification } \\
\text { Protection level id. } \\
\text { Protected buildings } \\
\text { plane generation } \\
\qquad \\
\text { Register precision } \\
\text { certification }\end{array}$ & $\begin{array}{c}\text { Data collection and } \\
\text { introduction from: } \\
\text { Provincial catalogue } \\
\text { General Plan catalogue } \\
\text { Special Plans } \\
\text { catalogues } \\
\text { Detail Plans catalogues } \\
\qquad \\
\text { Existing registers } \\
\text { contents generation }\end{array}$ & $\begin{array}{l}\text { Data collection and } \\
\text { introduction from: } \\
\text { Historical cadastre } \\
\text { Bibliography } \\
\text { Field work } \\
\text { Photographic report } \\
\text { Protected architecture } \\
\text { catalogue complete } \\
\text { generation }\end{array}$ & $\begin{array}{c}\text { Administrative } \\
\text { approval } \\
\text { Public participation } \\
\text { Amending introduction } \\
\text { Protected architecture } \\
\text { catalogue approval }\end{array}$ \\
\hline
\end{tabular}

\section{Conclusions}

As mentioned the database project not only aspires to be a management tool for professionals in heritage, but also a digital heritage portal, working basis for culture research and public dissemination.

It has already been said about the virtues of the system in terms of administrative and urban management, in the interest of preservation and enhancement use of invisible heritage for most of the population, but it is noteworthy that the project has a socio-economic dimension for young employment in sectors like restoration, culture dissemination and tourism.

The heritage database can also be the proposals collection platform to act on heritage through academic projects or dissertations aimed at refurbishment in technical disciplines, and local broadcasting campaigns in other academic disciplines.

SIPACV could be a databank of viable proposals for renovation, prepared by tutored post-graduate grant awarded by local administrations and private companies interested in promoting these projects; in so, University human and technological resources could be part of administration and company, by means of vocational training.

\section{References}

[1] Laboratorio di Documentazione, Analisi, Rilievo dell'Architecttura e del Territorio, Cassino University, Italy.

[2] Consorcio per la Gestione del Centro de Coordinamento delle Attività di Recerca Inerrenti il Sistema Lagunare di Venecia (CORILA).

[3] Bartolomei, C.; La documentazione dei Beni Culturali, Disegnarecon, vol. 3 $\mathrm{n}^{\mathrm{o}}$ 6, Bologna University, Italy, 2010. 
[4] Desiderio, M.L, Mancenelli, L., Negri, A.; SIGECweb: the Italian national informative system for cataloguing cultural heritage, ICCD, Instituto Centrale per il Catalogo e la Documentazione (MiBAC), EVA-Electronic Imaging \& The Visual Arts 2010, Florence, Italy.

[5] Instituto Andaluz de Patrimonio Histórico, online. http://www.iaph.es/ patrimonio-inmueble-andalucia/ 